\title{
The Research and Practice of the Training Mode of Local University Music Performance Professionals
}

\author{
Jia Zhu \\ Art College of Hainan Tropical Ocean University, Hainan Sanya 572022, China \\ zhujia1217@126.com
}

Keywords: Music performance; Applied talents; Training mode; Practical skills

\begin{abstract}
The training of local university music performance professionals is different from musicology profession, more different from the training of professional university music performance professionals, in this paper, we are aimed at the lack of training of local university music performance professionals, analyze reasons, position comprehensively, search for the job market in the new period, put forward the theory and the practice strategy of the training of performing major professionals' comprehensive abilities in local university.
\end{abstract}

\section{Introduction}

Since the new period, with the establishment and gradual development of the market economy, the art market also gradually mature, realistic society is becoming more and more urgent demand for music art talent, so the art market for art talent of basic quality, performance skills and comprehensive abilities are also becoming more demanding. Especially in today's art market, it attaches great importance to the comprehensive abilities of music performance professionals. It makes university further reform teaching, intensify efforts, focus on improving the quality of teaching, improve the comprehensive abilities of students. Because the training of music performance professionals is special, the training of comprehensive ability especially emphasis on following the rules of music performing arts, combine the requirements of cultivation of talents in the new period and social development trend, keep pace with the times, bring forth new ideas, in this way can we achieve the training objective of music performing professional talents in universities and colleges.

\section{Current Situation of the Training Mode of Local University Music Performance Major}

The Difference of Teaching and Curriculum with Musicology Profession Is not Obvious. Musicology profession on curriculum program is divided into three series, the first is the music theory course series, including Chinese and western music history, introduction to Chinese and foreign national folk music, introduction to art, music aesthetics; The second is the vocal music, instrumental music skills teaching course series, including vocal music performance, piano performance, instrumental music performance and basic theory of piano art history, the basic theory of singing; Third is composing theory and the command class series, course includes basic music theory and audio-visual and practice ear, and acoustic, melody, choral conductor, this is the ordinary university music performance interlinked professional curriculum, So one of the biggest problems in this teaching contents and curriculum is not outstanding performance "performance" of professional characteristics, and the difference with musicology professional is not obvious. 


\section{The Practice Teaching Form Is Single, the Target Is not Clear and Lack of Artistic Practice Tracking Management}

Setting up the local university music performance art practice curriculum, its final purpose is that through the art practice, the students will learn skills, techniques and theory knowledge, really exercise students' music talents and professional technical ability to work, in terms of the current local colleges music performance art practice curriculum settings, most of the existent forms are single, practice target is not clear and lack of art practice tracking management, some local colleges contact with the practice of professional performing art groups, but because of the form, the target of art practice is not clear, makes the random of music performance major increase, lack of management in the process of practice, some performing major students have no artistic practice, liking grazing, but we also give them the corresponding credits. Some universities, arranged for students of music performance in the art view, but the view is not equal to practice, the tour art practice for performing major students, also because of the unclear target, lack of the substance. Appreciation, demonstration, field trips, lecture or let students go home to arrange practice is some local colleges' practice form of music performance art, but the disadvantages of the practical courses were exposed by these practices, view v lecture give priority to listen, performing professional students can not participate, can not show their skills, stop the chance of knowledge and skills into the ability.

\section{Lack of Docking with the Job Market and Local Region Culture Linkage}

At present, there are many colleges and universities open music performing major, music performance major recruit students is also very hot, on the one hand, the phenomenon of "the quantity is high, but the quantity is not high" exist in teaching, on the other hand, it also lack of linkage with local culture and docking with the job market. No matter vocal performance, instrumental performance, dance performance, they are all highly applied professional, do the mode of combination of education, learning and performance, it must need regional cultural linkage, in line with the employment market, which is also the need of the practical ability of music performance professional graduates to dock the social service.

\section{On the Corresponding Measures for the Reform of the Training Mode of Music Performances in Local Colleges and Universities}

To Revise the Professional and Practical Teaching Syllabus for the Major of Music Performance. Local colleges and universities can fully combine their own characteristics, in line with the purpose of students can participate in the practice of Art, to revise the teaching outline which is in line with its own characteristics. In the course of music theory, in addition to some basic theoretical courses that are consistent with the music majors, should also set some special courses, according to the demand of employment, focus on the cultivation of students' comprehensive ability in music performance, such as stage performances, lines, audio and video recording technology, stage lighting and sound, computer music production and other skills, open instrumental ensemble, ensemble, accompaniment skills course for students of instrumental performance. Classifying and grouping teaching for students, same professional students to carry out a longitudinal choice, to carry out the chorus, singing, dance ensemble, collective teaching, horizontally develop different performing combination of teaching, such as the combination of vocal music and piano, the combination of piano and instrumental music, the combination of different instrumental music and the combination of rehearsal, vocal music and dance, etc. Such teaching can enrich the students' knowledge of performing majors in a large extent. it can also broaden the vision of music performances. Of course, such a combination of horizontal and vertical teaching will have to change the traditional one or two groups of classes in the form of teaching, the 
single tutorial system in teaching should be changed accordingly, according to the choice of students' horizontal and vertical direction, collocate dual tutor or multi tutorial system teaching, to do a diversified teaching and learning, to cultivate the comprehensive ability of the students to meet the needs of the society.

\section{Emphasizes the Social Demand and the Performance Practice Teaching}

The expansion of the students' enrollment of music performance majors also brought about the increasingly severe employment form of the professional graduates. Losing in the training mode of music professional and professional colleges and universities, directly affects the quality of personnel training, only the practice and teaching are carried out simultaneously can make the music performance professional students to meet the social needs, to meet the requirements of employment. Schools can actively engage in social activities, organize students' internship, internship performance, take the students to participate in various art competitions in the community, regularly organize professional reporting performances, to carry out the "weekend", "concert" and other practical forms, Improve students' practical ability, form the teaching of synchronization with theoretical teaching, the mode which combines performance with practice, become a comprehensive applied art talents to meet the needs of the society.

The construction of off campus performance base is also a measure to improve the practice ability of the professional students of music performance, set the performance base to second courses, the school can cooperate with local dance, theatre, art gallery, organize the students to perform at performance base, and carry out cooperative performance, and work together to carry out the creation and practice of work, in these cooperative practices, students can really learn the stage performance ability, stage strain capacity and related comprehensive knowledge ability. For such practical activities with the corresponding credit system, set up credit system of performance, winning credit system, social practice credit system, encourage students to participate actively in the art practice.

\section{Combine Teaching Practice of Music Performance with Local Characteristics and Actively Exploite Campus Cultural Activities Platform}

Local colleges and universities are the main part of higher education system in China. It aims to serve the regional economic and social development, focus on local training of high quality personnel. The vivid local music is the witness of the history of the local area, and is a member of the multi culture. It can provide materials for aesthetic education, but also bring new opportunities for the development of music education. The teaching of music performance in local colleges has the obligation and responsibility to promote and develop the local music. The introduction of local music into the category of professional teaching of music performances, but also highlights the characteristics of local colleges. Performing professional students learn singing, playing, performing the local traditional music, but also to broaden their employment direction, make the performance more accessible, more adapted to the needs of local aesthetic art market.

\section{With the Development of the Students, the Ability to Highlight the Cultivation of the People}

From the perspective of the development trend of the whole music performance profession, how to scientifically locate, carry forward the characteristics of running a school is a big direction. We are based on the premise of establishing the educational outlook based on the development of students, establish a diversified cultural view of music, taking music performance teaching as the carrier, to enhance students' interest in learning, pay attention to the cultivation of students' Humanistic Quality, at the same time, it is 
also conducive to the construction and development of music. The humanization, which popularize and praise people oriented, in terms of the ability of professional students to perform music performances, need special emphasis on the concept of school and teachers to update, Must be established in the teaching concept of the development of students, attention to the development of students' ability in teaching practice. Special emphasis should be put on the combination of comprehensive and personal, not only to pay attention to all students, but also to take into account the individual practice of each student, along with the balance and the development, take care of special students, to clear the goal of training, pay attention to the difference between the professional music and the music of professional music, prefer the training of students' practical ability in music performance, to meet their needs for the development of skills and the need for graduation, to enable students to develop a higher cultural quality, profound artistic accomplishment, knowledge of professional skills and creative music performance skills, eventually develop a high quality, innovative, applied music professional talent.

\section{Stressing Application and Reform the Teaching Mode of Music Performance}

In the past, the teaching of music performance in Colleges and Universities, without the barriers of teaching theory, students have a certain degree of knowledge of music theory, however, in general, the ability of knowledge and theory is limited. In order to integrate into the practical, students also need a longer time to adapt to the process. This is actually a problem of teaching and learning.

The professional level of the students who are in the school is uneven, lack of enthusiasm in the study of professional skills, coupled with the old teaching model, teachers' leading and students' initiative can not be fully reflected, teaching quality is difficult to get the best results, unable to meet the actual needs of the professional music performance. This situation can be changed by changing teaching methods. Try and construct a new teaching mode with the characteristics of application, in order to meet the needs of the students' ability of music performance. Changing the teaching methods from teachers as the center to students as the center, advocate autonomous, cooperative and inquiry learning methods, such pattern is innovative, focus on student's main body position, devotes to arouse student's study interest, enthusiasm and initiative, take the interactive inquiry, combination system, mentoring, cooperative forms etc. The formation of a personalized teaching pattern to meet the needs of different students, stimulate interest and participation, and ultimately improve the creative ability of all students' music performances.

\section{Strengthen Practical Teaching and Improve Students' Ability of Applying the Skills}

Students' growth is from the beginning of the practice. At first, they watch the shows of famous artists, not only to watch, but also must pay attention to the early masters of the repertoire of repertoire, ready for watching the show, listen to the music, consciously ask the students to listen with the questions, and after observing, they need to summarize, usually requires students to participate in competitions or school performances, accumulate stage experience, change the free mood from jerky. Next, school can cooperate with the performance company, let the students participate in the program design, project planning and performance. Students can also go out on their own, deeply learn from communities and villages, each class is a "art group", they can develop independent activities, can take the necessary performance tasks. Students can carry out the art observation, folk music, field surveys and other activities, go out and come in, make the process of teaching life is full of fragrance. Teachers can guide students to carry out concerts, songs and dances, festivals, festivals, etc. This can not only active campus culture, but also directly serve the masses, provide them with artistic vitality of the entertainment content, to meet the needs of the masses of the people's art life.

Of course, the comprehensive ability training of the professional students of music performance needs comprehensive application and innovative methods and strategies, for example, the construction of 
teaching staff, cultivate the atmosphere of campus culture, optimize the social environment, comprehensively play the role of social mechanisms and related functions, they are indispensable to students' comprehensive ability of music performance. The above mentioned method, is just one of the basic parts. More ways and strategies, we need to practice in the specific teaching process. I believe all the music educators work hard, they will contribute to the comprehensive development of students' comprehensive ability and physical and psychological quality of music performances.

\section{Summary}

Local music performance is a professional training of comprehensive development, comprehensive, innovative music professionals. The graduates' employment face television, song and Dance Theatre (Group), TV drama production center, publicity departments, cultural and educational institutions, such as departments, engage in teaching, singing, writing and music production, performance, stage organization planning, etc. Talent training mode is the sum of the specific training objectives and personnel specifications, with relatively stable teaching content and course system, management system and evaluation method, the process of implementing talent education, which is under the guidance of modern educational theory and educational thought. Local colleges and universities music performance professional talent need to adapt to the requirements of social employment, and should be targeted, effective in the training mode.

\section{Acknowledgement}

This research was financially supported by the research project of teaching reform of higher education in Hainan Province (No. Hnjg 2015- 54); the 2015 Hainan education science study topics of the "12th Five-Year Plan (No.QJY1251536); the Hainan Planning projects of philosophy and Social Sciences (No.HNSK14-124).

\section{References}

[1] Jia Zhu, Study on National Cultural Structure of Li Nationality Traditional Music Form in Hainan, Information Engineering Research Institute, Vol. 2, pp. 385-387, 2015.

[2] Man Wu, Training of students' comprehensive ability of music performance major in the new era, no. 2, pp. 209-210, 2014.

[3] Jia Zhu, The role of emotion in piano performance, Northern Music, vol. 35, no. 21, pp. 65, 2015.

[4] Yun Peng, On the teaching of music performance major in Local Colleges, Science \& Technology, no 30, pp. 60, 2014.

[5] Jia Zhu, The Training and Research for Multi-skill Novel Practical Talents based on the Analysis of Hainan Undergraduate College Music Major--Take Hainan as an Example, Journal of Qiongzhou University, vol. 21, no. 1, pp. 114-117, 2014.

[6] Feng Liu, The music performance curriculum reform based on the mode of performing and studying combination, Higher Education Forum, no. 9, pp. 44-46, 2013.

[7] Wen Ma, On the Problems in the Training Mode of Music Performance Talents and Solutions, Journal of Nanchang Normal University, Vol.35, No.04, pp. 73-76, 2014.

[8] Xiaolan Lei, Talent cultivation and strategy of music performance specialty in local colleges and Universities, Art Education, No.01, pp. 52-53, 2013. 
[9] Longrui Pan, On the Construction of the Normal Performing Personnel Training Mode, Journal of Jiangxi Institute of Education, Vol.30, No.4, pp. 42-44, 2009.

[10] Xiangyang Liu, Reflections on the curriculum setting of music performance major in Comprehensive University, Journal of Social Science of Jiamusi University, Vol.23, No.06, pp. 134-135, 2005. 